\title{
A Study on the Effect of Continuation Task on the Usages of the Second Language in the Argumentative Writing
}

\author{
Honggai Cai ${ }^{1}$ \\ ${ }^{1}$ School of English, North China Electric Power University, Baoding, China \\ Correspondence: Honggai Cai, School of English, North China Electric Power University, Baoding, China.
}

Received: May 5, 2019 Accepted: June 2, 2019 Online Published: June 4, 2019

doi: $10.5539 /$ elt.v12n7p52 URL: https://doi.org/10.5539/elt.v12n7p52

\begin{abstract}
The purpose of this study is to investigate the effect of continuation writing on the usages of the second language in the argumentative writing. The research questions in this study are as follows: 1) Whether the language application of the second language learner exists in coordination with the reading text; 2) Whether the continuation writing can promote the learning of vocabulary and phrases in the second language learning; 3)whether the comparative continuation reduce the learner's linguistic bias. In this study, the experimental group was asked to read the materials first, and through the guidance, attention, and other measures to strengthen the understanding of the reading materials while the control group without reading materials ahead of time blindly write an essay on the same topic and then compare them by corpus. The results of the study indicate that the alignment effect of the experimental group was stronger. The subjects are able to use the words and phrases that appear in the reading materials at high frequency. The research results can provide reference for the continuation writing teaching and research in the field of the second language.
\end{abstract}

Keywords: argumentative writing, continuation writing, alignment

\section{Introduction}

As far as English learning in our country is concerned, learners lack the opportunity to communicate directly with native speakers and chances of actually using English to listen and hear are fewer. They lack the real situation of using English. However reading and writing in English learning are less affected by this real condition. Today it is an internet age and the original native language reading materials are readily available. They only need to interact with the text and do not need to communicate directly with native speakers. Therefore, by reading the original native language articles, the combination of understanding and output of writing authentic English articles are in line with the characteristics of China's current English learning situation, thus improving the efficiency of English learning (Wang, 2012). Continuation writing is an effective way to improve the writing output of students by closely combining reading input with writing output. That is choosing an article that meets the student's language level and cutting off the ending half. When the students finish reading the first half of the article, and then continue to write the second half based on the understanding of the first half. In order to ensure the continuity and accuracy of the continuation writing, the learner will continue to read in depth the articles and analyze the language expressions used by the author in the first half. The continuous interaction between learners and reading materials and authors strengthen learners' understanding of the reading texts and enhance learners' master of language. Thus the level of learners' writing will be higher than their own writing level. The learners' writing is in line with the original work, just like interacting with native speakers whose English level is higher than their own language level. Thus the writing can produce a "flattening effect" (Wang, 2010), and achieve a rapid improvement of foreign language learning.

From the interaction theory of Vygotsky (1962) to the interactive collaborative model of Pickering and Garrod (2004), these are the theoretical foundations for continuation writing after reading. Interaction is used to describe the state of mutual adaptation and coordination between the two sides of the dialogue, mainly because the speaker tends to use words or sentence patterns that the other party has just used. Continuation writing after reading extends the "alignment effect" from interpersonal interaction to the interaction between human and reading text, especially the phenomenon that learners repeatedly imitate the language form reading materials. Wang (2016) put forward the "continuation theory" and perfected the theoretical basis for reading and writing. The outstanding feature of the "continuation" task is that the discourse is incomplete, stimulating the learner to 
complete and expand, and in the process of output writing, the previous text works as a sample. The continuation writing combines comprehension with production, which has been proved to be beneficial to the Second Language Acquisition (SLA). Such continuation tasks include continuation reading, continuation writing, and continuation translation, collectively referred to as "sequel" (Wang, 2016)

Comparative continuation writing is another variant of continuation writing after reading. Argumentation has been regarded as a challenging writing type in academic writing in that it integrates skills required in other text genres with critical thinking ability demanded. Compared with the ending of article removed and then continue to write, the comparative continuation of the essay is to turn a complete article into a renewable reading material, different from the narrative of the story. The previous essays on studies of the continuation writing are more concerned with the narratives. Only Zhang (2017) found that the influence of different genres on the alignment is different. This study is intended to probe whether and to what extent the continuation task affects argumentative writing among EFL learners in China. The research results indicated that the effect is stronger and the frequency of errors is lower, but the amount of language output in the narrative is greater than that of the argumentation writing. Xiong (2018) indicated that the continuation writing of argumentative can promote the high-frequency use of phrases and vocabulary in the reading materials, which can significantly reduce the emergence of Chinese English.

This paper attempts to use the complete article as a continuation of the material to explore the impact of the essay on the use of second language. The research questions in this paper are as follows: 1) whether the language application of the learner exists in coordination with the reading text; 2) whether the continuation of the paper can promote the learning of the second language vocabulary and phrases; 3) whether the comparative continuation reduce the learner's linguistic bias.

\section{Literature Review}

Wang Chuming and his team make a series of study about the continuation writing such as the introduction of foreign theory, further improvement in China social context and propose of the theory of "sequel" in 2016 as well as the implementation of a series of empirical research. Wang (2009) proposed "learn together, use together"principle, during which L2 learners interact and align with the original text continuously, and their written production can be improved. Wang (2010) proposed the combination of interactive collaboration and foreign language teaching, and Wang (2011) pointed out that the effective path of learning foreign languages is "learn together, use together"principle. Wang (2012) also wrote an article pointing out the advantages of continuation writing and the specific methods of operation. Wang (2014) emphasized that learners actively output and promote foreign languages. Language needs to be imitated through interaction in rich contexts, and strengthen language output during which L2 learners interact and align with the original text continuously, and their written production can be improved. They introduced the theoretical foundation and operation mode of the continuation writing in a comprehensive way, and then put forward the "sequel" theory, pointing out the "continuation" teaching design and sequel classification. They pointed out that the continuation task is effective in enhancing English narrative writing. The comparative continuation argumentation can overcome the limit of continuation after reading according to Wang (2016). Wang (2018)'s latest research specifically pointed out the specific operation steps of "multiple rounds of continuation writing" and "comparative continuation of writing" to solve the problem of weak interaction and insufficient language alignment.

A series of empirical studies by other experts and scholars also confirmed that continuation writing can promote L2 learning. The empirical research on continuation writing in promoting second-language vocabulary learning: Jiang and $\mathrm{Tu}(2016)$ found that continuation writing is more effective than summary writing in promoting the learners' verbs, nouns, and adjectives. Sun and Wang (2018) found that continuation writing can improve the article learning of high-level and low-level English learners. Xiong (2018) found that the continuation can be used to promote the high-frequency use of phrases and vocabulary in reading materials, which can significantly reduce Chinese English. However, Zhang (2017) have found that different effects on the alignment through the empirical comparison of the argumentation and the narrative. The alignment effect in argumentation is more powerful than the narratives and the frequency of the errors is lower than those of the narrative. But the linguistic output of continuation writing in narratives is greater than the argumentation. Then Zhang et al. (2019) found that continuation after reading can promote vocabulary acquisition more than continuation after listening. Jiang and Chen (2015) found that continuation can significantly improve the accuracy and complexity of English composition. Gu and Zhou (2018) found that in the process of returning to text, the learners' attention focus on the linguistic forms of texts, through various forms of interactive guidance. It can significantly improve the lexical level of alignment and writing accuracy of low level students. 


\section{Empirical Research}

\subsection{Research Questions}

This study attempts to answer the following research questions:

1) Does the learner's language use exist in alignment with the reading text in the comparative continuation?

2) Can the comparative continuation promote the learning of vocabulary and phrases of second language learners?

3) Can the comparative continuation reduce the learner's linguistic bias?

\subsection{Participants}

Two classes of first-graders majoring in a science and engineering in Baoding participated in the experiment. They are in the second semester of the freshman year. The two classes were parallel classes, specializing in electronics and communication, energy and power engineering, etc. Each class has 30 students. Before the experiment, the latest writing scores of 60 students in College English Band4 were $t$-tested $(t=.837 \mathrm{p}>0.5)$. There was no significant difference in the English writing between the two groups. One of the classes was randomly selected for the experiment and the other class is a control class.

\subsection{Experimental Steps}

The students in the control class, without reading materials, were asked to complete a composition equivalent to the writing in College English Band 4 in 45 minutes. The number of words is no less than 150, not more than 180. The title of the composition is "about graduate education in China". Blind writing is required, discussion is not allowed, and dictionaries or other references are not allowed. However each participant in the experimental class was given reading material beforehand. That could be used to be compared with when the students were asked to write the argumentation. The topic of the reading material are called "graduate education in Great Britain". Participants are also required to write an essay on the same topic within 45 minutes after reading the article. The same number of words is required to be no less than 150 and no more than 180 . This article discusses the situation of Chinese students' further graduate education in the UK. The topic is familiar to the participants, so that they have ideas to express, and they will face such choices in the future. The participants are asked to read the materials for twenty minutes before the writing. At the same time they learn, circle or underline relevant words and phrases under the guidance of the teacher. At the same time teacher will explain and analyze the usages of key words and expressions. After these participants continue to write the views on Chinese postgraduate education in a comparative way, that is, compared with the main points in the reading materials and write about the postgraduate graduate education in China.

\subsection{Data Collection and Analysis}

All the essays of the experimental class and the control class are uploaded to the internet Pigai (www.pigai.org), which is composition correction software. In this experiment, a total of 60 compositions were collected in two groups. According to the experimental class and the control class, two small corpora were established, each with 30 essays.

\subsection{Corpus Search}

In this study, the experimental group and the control group were compared with the reading materials at the vocabulary and phrase level. The statistics are divided into two levels: 1) statistics on the frequency of occurrence of 10 target words and phrases; 2) statistics about 10 high-frequency keywords appearing in the experimental group and the control group. The corpus retrieval tool is AntConc 3. 4.4

\section{Results and Discussion}

\subsection{Target Words and Phrases}

This study requires the participants to compare the views of British graduate education and Chinese postgraduate study. Before the test under the guidance of the teacher, the words and phrases used for comparison of viewpoints were marked and analyzed in the reading materials. Table 1 is the 10 target words and phrases examined in this study. 
Table 1. The target words and phrases

\begin{tabular}{|c|c|c|c|c|}
\hline Types & & $\begin{array}{l}\text { Target Words \& } \\
\text { Phrases }\end{array}$ & $\begin{array}{l}\text { Part of } \\
\text { Speech }\end{array}$ & English Meaning \\
\hline \multirow{3}{*}{\multicolumn{2}{|c|}{$\begin{array}{l}\text { Signal } \\
\text { Phrases }\end{array}$}} & Compared with & & In comparison with \\
\hline & & In contrast & & While, but \\
\hline & & On the contrary & & But, while \\
\hline \multirow{7}{*}{$\begin{array}{l}\text { Words } \\
\text { Phrases }\end{array}$} & $\&$ & Resume & n. & A summary of your academic and work history \\
\hline & & Tuition & n. & $\begin{array}{l}\text { The money that you pay to be taught, especially in a college } \\
\text { or university }\end{array}$ \\
\hline & & $\begin{array}{l}\text { Cultural } \\
\text { Differences }\end{array}$ & & The quality of diverse or different cultures \\
\hline & & Degree & n. & $\begin{array}{l}\text { The qualification obtained by students who successfully } \\
\text { complete a university or college course }\end{array}$ \\
\hline & & Domestic & adj. & Inside a particular country; not foreign or international \\
\hline & & Academic & adj. & $\begin{array}{l}\text { Connected with education, especially studying in schools and } \\
\text { universities }\end{array}$ \\
\hline & & Overseas & adj. & $\begin{array}{l}\text { Connected with foreign countries, especially those separated } \\
\text { from your country by the sea or ocean }\end{array}$ \\
\hline
\end{tabular}

\subsection{Alignment of Vocabulary and Phrases}

With the help of the corpus software AntConc 3. 4. 4, the statistics indicate alignment of phrases and words between the two groups in the experiment. Table 2 lists the number of occurrences of the target words and phrases in the experimental and control groups. The control group has no reference to reading materials and no teacher has interactive guidance. The probability of occurrence of these ten target words in the control group is extremely low, and most students use informal and non-academic vocabulary instead: such as "cost" instead of "tuition", "study" not "academic performance", and "our home" instead of "domestic". "In contrast to" "compared with"and "on the contrary" can be used to indicate contrast, which sound much more formal and academic however the control group used more "but". Since "overseas" is word used in composition title, "overseas" has a very high frequency not only in the experimental group but also in the control group. That is 263 in the control group; 241 in the experimental group. 263 in the control group is higher than the 241 in the experimental group. Although the two groups wrote the essays on the same topic, the vocabulary alignment in the experimental group was significantly stronger than that of the control group due to the reference of the reading materials and the teacher-directed textual interactions. It can be seen that the learner tends to align with the reading materials at the lexical level, and resorts to the words that have appeared in the reading materials when they make a comparative writing.

Table 2. Frequency of occurrence of target words in experimental and control groups

\begin{tabular}{llll}
\hline & Target Words \& Phrases & $\begin{array}{l}\text { Test Group } \\
\text { Frequency }\end{array}$ & $\begin{array}{l}\text { Control Group } \\
\text { Frequency }\end{array}$ \\
\hline 1 & Compared with & 220 & 31 \\
2 & In contrast & 236 & 26 \\
3 & On the contrary & 210 & 21 \\
4 & Resume & 123 & 16 \\
5 & Tuition & 210 & 13 \\
6 & Cultural differences & 116 & 35 \\
7 & Degree & 175 & 2 \\
8 & Domestic & 196 & 0 \\
\hline
\end{tabular}




\begin{tabular}{llll}
\hline 9 & Academic & 153 & 47 \\
10 & Overseas & 241 & 263 \\
\hline
\end{tabular}

After clear understanding the direction of the continuation task the subjects in the experimental group carefully read the original text. Firstly, the viewpoints for comparison were found. The level of postgraduate education in the UK was high which can provide students with pioneering theoretical knowledge, advanced laboratory equipment and first string research teams. But the tuition fee is a little bit high for average middle class family. After the reading text, participants compared British graduate education with Chinese postgraduate study, they have their opinions about the differences and similarities of two countries. With the teacher's interactive guidance participants increase their attention on the words and phrases which can be used in their continuation writing. Because they will rely on such expressions to achieve the goals. The motivation for using such words and expressions are strong. So the participants will actively think about their usage and use them in their own writing. Wang $(2012,2013)$ once wrote that for the new words and phrases, once the students actively understand and use, the memory can be deepened. Just as the popular principle "learning by doing". By using such words and phrases you ultimately learn them in heart. In turn, students' sense of achievement in learning is improved, and interest and motivation in learning are enhanced.

\subsection{Language Bias}

This study uses Wang (2014) model to classify the language bias of English learners in China. Language bias is divided into form bias and meaning bias. Form biases include the tense, subject-verb agreement, article, non-predicate verb, and verb. Meaning bias is actually Chinese English. It refers to English that is not in conformity with English expression habits and has Chinese characteristics and they are influenced by Chinese way of thinking or culture. For example, "learning knowledge"is Chinese English. The correct English expression is "acquire knowledge". Another example is "the price of apple is very expensive recently." however the authentic English expression is "The price of apples is very high recently". Such kinds of examples are numerous in the first stage of learning English

The statistics of the biases are summarized in the following table. The procedure of analyzing the errors are as follows: first, the errors are marked. Then, based on Wang (2014) the classification criteria, and their statistical methods to count the frequency of errors in each hundred words. The statistical results are shown in Table 3.

Table 3. The bias types

\begin{tabular}{llllllll}
\hline & $\begin{array}{l}\text { Form Bias } \\
\text { Subject-verb } \\
\text { agreement }\end{array}$ & Article & Link verb & Infinitive & Tense & total & \\
\hline Test Group & 0.37 & 0.32 & 0.15 & 0.26 & 0 & 1.00 & 0.06 \\
Control Group & 0.44 & 0.32 & 0.23 & 0.28 & 0 & 1.17 & 0.34 \\
\hline
\end{tabular}

It can be seen from Table 3 that there is no significant difference between the experimental group and the control group in the form bias. When it comes to subject-verb agreement, 0.37 in test group versus 0.44 in control group, there is no significant difference between two groups. The form bias of article 0.32 in both two groups and the tense form bias 0 in control and test group, whose value are exactly the same. Since the argumentative essays usually employ the general present tense to prove their points without variations of tenses, neither the experimental group nor the control group has not tense form bias. This experiment reflects that the reading material cannot help the learner to reduce the form bias. However, the meaning bias in the test group was significantly less than that in the control group. The 0.06 meaning bias of the experimental group was significantly less than that of the control group of 0.34 . That affirms that the reading text can help reduce the meaning bias.

\section{Conclusion}

This study finds that the continuation task can enable the L2 learners to imitate the words and phrases appearing in the reading material and produce alignment with the reading materials. It can reduce the bias of language meaning, and the alignment effect on the bias of language form is not obvious. The comparative continuation lack of fascinating story lines, the learners are more concerned with the use of words and phrases in reading 
materials to improve the persuasiveness of evidence. Zhang (2017) also found that the total number of vocabulary and phrases in argumentative essays were more than that of the narratives. The corpus statistics of this study confirm that the number of alignment of words and phrases in the continuation writing is very high. The study also confirmed that a comparative continuation in the argumentative writing can also achieve alignment Wang (2016). However, due to the small number of participants, and the difficulty of reading materials are hard to control this study can work as a preliminary study and shed some light on the continuation writing in the argumentative writing.

\section{Acknowledgments}

This study was financially supported by the Fundamental Research Funds for the Central Universities (2015MS71).

\section{References}

Jiang, L., \& Chen, J. (2015). The impact of continuation writing on the accuracy, complexity and fluency of English writing language. Modern Foreign Languages, 3, 366-375.

Jiang, L., \& Tu, M. Y. (2016). Study on the role of continuation writing in second-language vocabulary learning. Modern Foreign Languages, 6, 819-829.

Peng, H. Y. (2017). An Empirical Study of English Learners' Writing Coherence. Journal of PLA University of Foreign Languages, 4, 87-92.

Wang, C. M. (2009). Learning with the accompanying continuation method with the principle. Chinese Foreign Language, 5, 53-59.

Wang, C. M. (2012). Continuation after reading is an effective method to improve the efficiency of foreign language learning. Foreign Languages, 5, 2-7.

Wang, C. M. (2014). Content to create language to imitate - the basic idea of effective foreign language teaching and learning. Foreign Languages, 2, 42-48.

Wang, C. M. (2015). Continuation after reading effectively promote learning. Foreign Language Teaching and Research, 5, 753-762.

Wang, C. M. (2016). Promoting learning with "continuation". Modern Foreign Languages, 6, 784-793.

Wang, C. M. (2017). From "writing to promote learning" to "to continue learning". Foreign Language Teaching and Research, 4, 547-556.

Wang, C. M. (2018). How to improve the intensity of interaction in continuation. Foreign Language Circles, 5, 40-45.

Wang, M., \& Wang, C. M. (2014). The alignment effect of continuation. Modern Foreign Languages, 4, 501-512.

Xiong, S. H. (2018). Research on the alignment Effect of Contrasting Continued Writing. Journal of PLA University of Foreign Languages, 9, 85-92.

Zhang, X. Q., \& Zhang, Q. (2017). Study on the difference of the influence of continuation on collaboration in different genre readings. Foreign Languages, 3, 90-96.

\section{Copyrights}

Copyright for this article is retained by the author(s), with first publication rights granted to the journal.

This is an open-access article distributed under the terms and conditions of the Creative Commons Attribution license (http://creativecommons.org/licenses/by/4.0/). 